\title{
Alterations in leaf photosynthetic electron transport in Welsh onion (Allium fistulosum L.) under different light intensity and soil water conditions
}

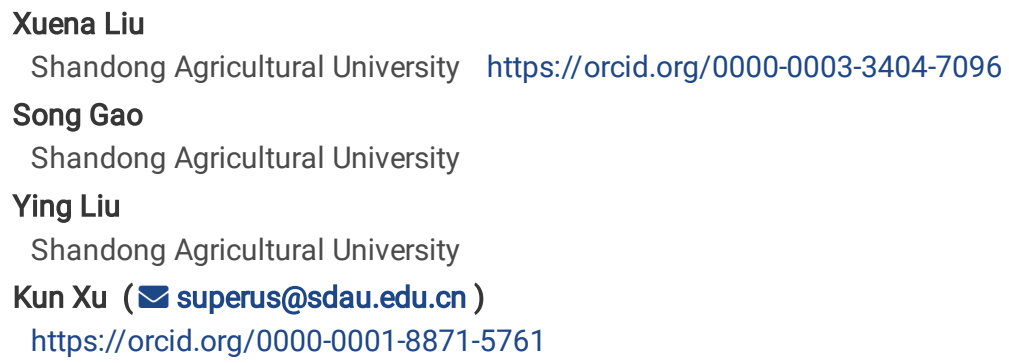

Research article

Keywords: Welsh onion; High light; Drought; Photosynthesis; Photosystem; Photoinhibiton

Posted Date: August 19th, 2019

DOI: https://doi.org/10.21203/rs.2.13123/v1

License: (c) (i) This work is licensed under a Creative Commons Attribution 4.0 International License. Read Full License

Version of Record: A version of this preprint was published at Plant Biology on September 29th, 2020. See the published version at https://doi.org/10.1111/plb.13165. 


\section{Abstract}

Background: Welsh onions are often affected by stressful environments, such as high light and drought, during summer cultivation, which hinders their growth. To date, few studies have focused on leaf photosynthesis of Welsh onions during summer. We used carbon dioxide assimilation and OJIP transient and MR curves to analyze the photosynthetic characteristics of Welsh onions. Results: The results showed that strong light and drought could lead to a decrease in leaf pigment content. Simple high light stress caused a decrease in the net photosynthetic rate through stomatal limitation, while the simple drought treatment and the two stress factors combined caused a nonstomatal limitation. PSII energy distribution indicated that strong light and drought stress reduced the photochemical quantum efficiency of PSII. OJIP curve analysis showed that FO and FJ were increased, Fm was decreased, and a distinct K-phase was induced. In addition, OJIP parameters, including RC/CSO, TRO/ABS, ETO/TRO, and PIABS, were significantly reduced. MR analysis showed that strong light and drought stress blocked MR transients, leading to a gradual decrease in VPSI and VPSII-PSI. Conclusions: In general, the photosynthesis of Welsh onion was inhibited by high light and drought, which destroyed the receptor and donor side of PSII and reduced the electron transport capacity of PSII and PSI.

\section{Background}

In the summer in northern China, a combination of high irradiance, high temperature and water stress (i.e., drought) is very common[1]. These limiting factors usually last a long time in the summer, which seriously affects plant growth and survival. When exposed to both drought and high light, plants respond with defensive reactions that involve more efficient water use, maintain high carbon dioxide assimilation with few stomatal openings, and initiate several photoprotective measures [2, 3]. Some studies have shown that photosynthesis is affected when plants are exposed to two or more stresses in the environment [4] Photosynthesis is the main physiological process of plants. The two photosystems [Photosystem I (PSI) and Photosystem II (PSII)] are vulnerable to damage during photosynthesis [4, 5].

Drought stress can induce stomatal closure and reduce the maximum quantum efficiency of PSII, resulting in reduced photosynthesis[6, 7]. As drought progresses, photosynthetic carbon assimilation and growth become limited. Photoinhibition occurs in plants when the amount of available light exceeds that required for photosynthesis[4, 5, 7]. PSII is the main target of photosynthetic photoinhibition $[7,8]$. The photosynthetic electron transfer process is driven by light excitation from $\mathrm{H}_{2} \mathrm{O}$ to coenzyme II $\left(\mathrm{NADP}^{+}\right)$. After the photosynthetic pigment absorbs light energy, it concentrates the energy in the reaction center, causing charge separation and a photochemical reaction. PSII takes electrons from water, oxidizes the water, releases oxygen, and then PSI transfers the electrons to $\mathrm{NADP}^{+}$and reduces the NADP ${ }^{+}$to NADPH, which passes through a series of electron carriers, such as plastoquinone (PQ), plastocyanin $(P C)$, the cytochrome $b_{6} f$ complex $\left(C y t b_{6} f\right)$, and ferredoxin $(F d)[9,10]$. Any change in the sites of the electron transport chain affects photosynthetic efficiency. The existing techniques, including use of the fast chlorophyll fluorescence induction kinetics curve (OJIP curve) and the modulated $820 \mathrm{~nm}$ reflection curve (MR curve), can be used to study the changes in the photosynthetic electron transport chain[11]. As the name suggests, the typical OJIP curve includes phases $0, \mathrm{~J}, \mathrm{I}, \mathrm{P}$, etc., which contain a large amount of information about the far-end photochemical reactions of the PSII reaction center. Through JIP-test analysis, changes in the photosynthetic apparatus of plant material under the influence of environmental factors can be obtained. Determining the modulated reflection mode at $820 \mathrm{~nm}$ is an effective way to study the redox state of PSI under continuous light[12]. In fully dark-adapted plant leaves, the PSI reaction center and the $\mathrm{P}_{700}$ primary electron donor (PC) were in a reduced state. After illumination, $\mathrm{P}_{700}$ and PC were converted to an oxidized state. Therefore, the reduction of $\mathrm{PSI}$ and PC can result in a decrease in absorbance at $820 \mathrm{~nm}$, while the oxidation of PSI and PC can increase the absorbance[13].

Welsh onion (Allium fistulosum L.), the most important seasoning vegetable in Asia, is mainly cultivated during summer, so the seedlings are susceptible to high light intensity and drought. It is necessary to evaluate the growth status of Welsh onions during summer. Surprisingly, there are no reports on the effects of the combined stresses of drought and high light on Welsh onions. In this experiment, we aimed to study the resistance of Welsh onion leaves under drought and high light conditions by examining photosynthetic parameters, focusing on the interaction between PSII and PSI using carbon dioxide assimilation, the OJIP curve and the MR curve. Our research further elucidates the photosynthetic reaction mechanism of Welsh onions under drought and high light stress and provides a theoretical basis for summer planting.

\section{Methods}

\section{Plant material and experimental design}

'Zhangqiu', a typical Chinese Welsh onion cultivar, was used as the plant material for all experiments. The Welsh onion seeds, obtained from Taian Denghai Wuyue Taishan Seed Industry Co., Ltd., were rinsed with sterilized distilled water, sown in plugs containing substrate, and grown in a greenhouse with standard irrigation and fertilization. Representative seedlings with four leaves were transferred to plastic pots (diameter $110 \mathrm{~mm}$, height $140 \mathrm{~mm}$; four seedlings per pot) containing $1000 \mathrm{~g}$ substrate composed of a sandy loam-soil: peat mixture (1: 1, v: v). The experiment was designed using a two-factor random block design. Factor $A$ was the shading treatment and included no shading $(\mathrm{N})$ and $20 \%$ shading $(\mathrm{S})$. Factor $\mathrm{B}$ was the water stress treatment and included drought conditions ( $40 \%$ of field capacity, D) and a normal water supply ( $80 \%$ of field capacity, W). There were four treatments, ND, NW, SD, SW. In the ' $N$ ' treatment, plants were exposed to natural conditions. Plants in the 'S' treatment were maintained on a plastic tunnel covered with shade cloth with a retention capacity of $80 \%$ of sunlight. To prevent the roots of the potted seedlings 
from absorbing water by capillary action from the ground, a watering basin was placed under each pot. A rainproof shelter was set up in the treatment area, the shelter was opened before rain events and was closed on sunny days. The plants were watered once daily at 09:00 using the pot weighing method to estimate soil moisture. Each treatment was replicated three times, and each replicate included twenty seedlings. In addition, HOBO Data Loggers (MicroDAQ.com, Ltd., NH, USA) were fixed around the test plants of each treatment to record the photosynthetically active radiation (PAR) and air temperature every $30 \mathrm{~min}$ (Fig. 1). All measurements were conducted at 10 and $20 \mathrm{~d}$ of treatment unless otherwise stated.

\section{Leaf pigments}

For each treatment, $0.51 \mathrm{~cm}^{2}$ leaf discs were cut from functional leaves. Five discs were immersed in $25 \mathrm{~mL}$ tubes with $20 \mathrm{~mL}$ of $95 \%$ ethanol, incubated in the dark at $25^{\circ} \mathrm{C}$, and then extracted for $24 \mathrm{~h}$. The amount of pigment in the solution was quantified using an ultraviolet-visible spectrophotometer (UV-2450, Shimadzu, Japan) as described in Zhao[14].

\section{Photosynthetic gas exchange measurements}

Using a CIRAS-3 portable system equipped with a $1.75 \mathrm{~cm}^{2}$ leaf chamber, we measured the net photosynthetic rate (Pn), stomatal conductance (Gs) and substomatal $\mathrm{CO}_{2}$ concentrations (Ci) between 8:00 and 11:00 in the afternoon. For all the gas exchange measurements, the constant flow rate was set at $200 \mu \mathrm{mol} / \mathrm{s}$, the $\mathrm{CO}_{2}$ partial pressure was $380 \mu \mathrm{mol} / \mathrm{mol}$ (unless otherwise stated), and the leaf temperature was $25^{\circ} \mathrm{C}$. The relative air humidity was set between $60 \%$ and $70 \%$. The photon flux density (PFD) was provided by a mixture of red ( $90 \%$ ) and blue (10\%) LEDs in the leaf chamber. All gas exchange measurements were taken from the youngest, fully expanded leaf, and corrected for diffusive leaks between the cuvette and the surrounding atmosphere. The diurnal variation in photosynthesis was measured using a CIRAS-3 portable photosynthetic apparatus. The functional leaf assay was selected, and the measurements were taken from 7:00-17:00 every $2 \mathrm{~h}$. Three leaves were chosen for each treatment as repeats.

\section{Chlorophyll fluorescence}

Using the Mini-Imaging-PAM chlorophyll fluorescence system (Heinz Walz GmbH, Effeltrich, Germany), we performed the chlorophyll fluorescence imaging in detached leaves from the four treatments. Plants used for chlorophyll fluorescence were dark adapted for 30 min before measurement. We acquired images of the effective PSII quantum yield [Y(II)], the quantum yield of regulated energy dissipation [Y(NPQ)], and the quantum yield of nonregulated energy dissipation $[\mathrm{Y}(\mathrm{NO})]$.

\section{Measurements of chlorophyll a transient fluorescence}

Chlorophyll a transient fluorescence was measured with dark-adapted leaves (in dark for $1 \mathrm{~h}$ ) at room temperature $\left(25^{\circ} \mathrm{C}\right)$ by a Handy PEA fluorometer (Hansatech Instruments, UK). Dark-adapted leaves were illuminated for $1 \mathrm{~s}$ with $3000 \mu \mathrm{mol} / \mathrm{m}^{2} / \mathrm{s}$ while chlorophyll fluorescence was induced. A typical OJIP curve resembles the different fluorescence states; the first rise from the origin is denoted as 0 which ascends to an intermediate state (the $\mathrm{J}$ step, at $2 \mathrm{~ms}$ ) followed by a second slower rise involving a second intermediate (the I step, at $30 \mathrm{~ms}$ ), while the $\mathrm{P}$ step is the maximum fluorescence measured. To compare measurements made on different samples, all values of fluorescence were standardized and analyzed with the JIP-test[9]. The JIP-test parameter used in this study and its formulae and explanation are listed in Supplementary Table 1.

\section{MR analysis}

The MR transient was measured with a Multi-Functional Plant Efficiency Analyzer (M-PEA, Hansatech Instruments, UK) as described by Strasser[12]. Before measurement, the plants were dark adapted for $20 \mathrm{~min}$. MR was expressed as MR/MRo, where MR represented the modulated reflection signal during illumination, $\mathrm{MR}_{0}$ was the value at the onset of the actinic illumination, and $M R / \mathrm{MR}_{0}$ represented the value of the $820 \mathrm{~nm}$ reflection at the onset of actinic illumination. The maximal decrease in the slope $\left(\mathrm{V}_{\mathrm{PSI}}\right.$, the maximum PSI oxidation rate) and the maximal increase in the slope ( $\mathrm{V}_{\mathrm{PSII}-\mathrm{PS} \text {, }}$, the rate of PSI reduction) were derived from the MR/MR .

\section{Statistical analysis}

Experimental data were collected from the four treatments in a random order and using three independent replicates. The data are expressed as the mean \pm standard deviation of three independent experiments. All statistical analyses were performed using DPS software. Calculations were performed using one-way ANOVA and Duncan's multiple range test. $p<0.05$ was considered to be statistically significant.

\section{Results}

\section{Leaf pigment and photosynthetic gas exchange parameters}

Table 1 shows that the chlorophyll and carotenoid contents and Pn decreased significantly under drought conditions, with decreases of $19.1 \%$, $21.1 \%$, and $64.5 \%$ under high light, and $20.7 \%, 18.7 \%$, and 55.1 , respectively, under $20 \%$ shading. Compared with natural light, shading increased the leaf chlorophyll and carotenoid contents, which increased by $4.9 \%$ and $9.4 \%$ under drought conditions and by $7.0 \%$ and $6.2 \%$, respectively, under 
normal irrigation conditions. As the processing time progressed, the effects of high light and drought on plants increased. The chlorophyll content, carotenoid content and net photosynthetic rate of SW were significantly higher than those of the other three treatments at $20 \mathrm{~d}$. The chlorophyll content of SW was $49.2 \%, 34.3 \%$, and $45.0 \%$ higher than that of ND, NW and SD, respectively. The carotenoid content of SW was 37.6 . \%, 32.3\%, and $27.3 \%$ higher, and the Pn was 6.3, 0.7, 2.3 times higher than the corresponding values of the other treatments. With prolonged drought stress time, the Pn decreased significantly. At $10 \mathrm{~d}$, compared with SW, the net photosynthetic rate of ND, NW and SD decreased significantly, while the Gs and Pn showed the same trend, and the Ci decreased slightly, but this difference was not significant. We hypothesized that the decrease in Pn was due to the closure of the pores, resulting in a reduction in the carbon dioxide supply. When treated for $20 \mathrm{~d}$, the decrease in Pn was intensified, and the Gs trend was basically the same, while the Ci of ND and SD was higher than that of SW, which may be the reason for the decrease in Pn caused by nonstomatal limiting factors; NW showed a decrease in Gs and an increase in Ci, which may have been caused by stomatal factors.

The trends in the diurnal variation of Pn were similar under the different treatments, and all showed a "double peak" curve (Fig. 2). The highest peak appeared at approximately 11:00, and the Pn was the highest for SW. Between 11:00 and 13:00, as the PAR and temperature rose, the Pn dropped rapidly and peaked at approximately 15:00.

\section{The quantum efficiencies of PSII}

Hendrickson et al. (2004) noted that the excitation energy of PSIl absorption in plant leaves was mainly used in the following three ways: Y(II), $\mathrm{Y}(\mathrm{NPQ})$, and $\mathrm{Y}(\mathrm{NO})$. Under natural light, the photosynthetic mechanism operates quickly, and the light energy absorbed by the Welsh onion leaves was mainly used for photochemical processes and heat dissipation. SW had the highest $Y(I I)$, which was $22.1 \%, 20.0 \%$, and $14.1 \%$ higher than that of ND, NW, and SD, respectively. The Y(NPQ) was highest with NW and lowest with SW. The Y(NO) of ND was significantly higher than that of NW, SD, and SW by $15.0 \%, 13.7 \%, 12.9 \%$, respectively.

\section{OJIP curve and JIP-test}

All OJIP curves showed multiphase changes as the OJIP phase increased. At the O-step, the fluorescence yield was minimal because $Q_{A}$ was almost completely oxidized after dark adaptation. When exposed to saturated pulsed light, with the accumulation of $Q_{A}{ }^{-}$, the fluorescence yield gradually increased. Once $Q_{A}$ completely entered the reduced state, the PSIl reaction center was completely closed, and the quantum yield was no longer accepted. At this time, the maximum PF intensity $\left(F_{m}\right)$ was reached. The occurrence of points $\mathrm{J}$ and I was mainly related to the exchange of a reduced $Q_{A}$ with an oxidated $P Q$ molecule at the $Q_{B}$ site and the reoxidation of $P Q$. After $10 \mathrm{~d}$ of treatment, there was a significant difference in the change in the OJIP transient. Compared with that of SW, the Fm value of ND, NW, and SD decreased while the minimum PF intensity (Fo) increased (Fig. S1-A). This trend was more pronounced at 20 d. Fig.4 -A, D shows an induction curve normalized by the fluorescence value at point P. The normalized curve did not change significantly at $10 \mathrm{~d}$ but did at $20 \mathrm{~d}$; the fluorescence signal between the O-P step of ND and SD increased significantly, especially the J-step. In the SW treatment, the OJIP curve showed similar trends over all measured days. Fig.4 -B, E shows a subtraction process with NW as a control. Four treatments were significantly different in the J-phase. At $10 \mathrm{~d}, \triangle \mathrm{J}$ under ND and SD increased to 0.02 and 0.01 compared to that of NW, while that of SW decreased to 0.02. At $20 \mathrm{~d}, \Delta \mathrm{J}$ increased to 0.08 under ND and SD and decreased to approximately 0.03 under SW. First, the 0 -J phase normalization was performed for each treatment and then subtracted from each treatment with NW as a control (Fig.4 - C, F). At $10 \mathrm{~d}$, SD had a more obvious K peak than did NW. The difference between the treatments at $20 \mathrm{~d}$ was more noticeable than that at $10 \mathrm{~d}$. The K peak of the ND treatment was $11.6 \%$ higher than that of the NW treatment, while the difference between the SD and NW was not significant, and the K peak of SW was $15.3 \%$ smaller than that of NW.

A large amount of raw data was obtained from the OJIP curve. To better reflect the relationship between the kinetic curves and the material, the methods of Strasser based on the biofilm flow were used to calculate the energy flow and energy ratio to measure the given physical parameters[12, 16]. The variation in the interior of the sample material in a given state was used to establish a highly simplified energy flow model diagram. The data from the energy model diagram was used for the JIP-test. Compared with SW, the $F_{0}$ of ND, NW, and SD increased significantly at $10 \mathrm{~d}$, by $18.6 \%, 12.9 \%$, and $19.2 \%$, respectively. At $20 \mathrm{~d}$, the $\mathrm{F}_{\mathrm{O}}$ value was highest in ND and lowest in SW. The difference in $\mathrm{F}_{\mathrm{O}}$ between ND and SD was not significant. The $F_{m}$ value of SW was significantly higher than that of ND, NW, SD, by $29.6 \%, 16.6 \%$, and $17.1 \%$, respectively. The $V_{J}$ reflects the degree of closure of the active reaction center at $2 \mathrm{~ms}$ of illumination. The $\mathrm{V}_{\mathrm{J}}$ of ND and SD increased notably, while the difference between SW and NW was not distinct. When the donor side of the PSII (oxygen-releasing complex, OEC complex) was damaged, the chlorophyll fluorescence yield increased before the $\mathrm{J}$ point (approximately $300 \mu \mathrm{s}$ ), so the relative fluorescence value $\mathrm{W}_{\mathrm{K}}$ of this point increased as the donor of PSII. The degree of increase in $W_{K}$ represents the level of damage on the donor side of PSII. ND had the highest $W_{K}$, and SW had the lowest. Sm is typically used to characterize the size of the PSII reaction center PQ pool. At $20 \mathrm{~d}$, there was a significant difference in Sm between different treatments, with SW being the highest at $27.6 \%, 19.8 \%$, and $26.6 \%$ higher than those of $\mathrm{ND}, \mathrm{NW}$, and $\mathrm{SD}$, respectively. There were significant differences in the $\mathrm{PI} \mathrm{ABS}_{\mathrm{B}}$ of the Welsh onion leaves under each treatment, in which drought stress notably decreased the $\mathrm{PI}_{A B S}$, while the $\mathrm{PI}$ ABS was increased by $20 \%$ shading.

\section{MR curve}


$\mathrm{P}_{700}$ can absorb light at $820 \mathrm{~nm}$ when the light is in the oxidation state $\mathrm{P}_{700}{ }^{+}$, so the change in light absorption or reflection at $820 \mathrm{~nm}$ can represent

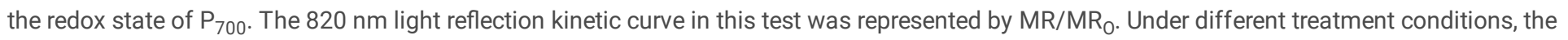
redox state of PSI changed in the leaves of Welsh onion. The lowest point of the MR/MR rapid decline phase represents the turning point of the PSI oxidation state. The fast decline phase of the synchronously measured MR/MRo curve changed at $10 \mathrm{~d}$, while the lowest point of the reduction was increased in ND, and the $M R / M_{0}$ drop rate $V_{P S I}$ was significantly reduced (Fig. 5). After $20 \mathrm{~d}$ of treatment, the rapid drop in the MR/MR of $N D$ was significantly shifted backward and increased. In addition, the $\mathrm{V}_{\mathrm{PSI}}$ of ND was notably reduced compared with that of NW, SD, and SW by $27.5 \%$, $20.5 \%$, and $48.9 \%$, respectively. For the rate of the reduction of $\mathrm{P}_{700}{ }^{+}$by electrons from PSII and the reduced PQ pool, the rate of increase of $\mathrm{V}_{\mathrm{PSII}} \mathrm{PSI}$ in ND was significantly reduced after $10 \mathrm{~d}$ of treatment. After $20 \mathrm{~d}$ of treatment, the rate of increase of MR/MRo was highest in SW, followed by NW and SD, and was the lowest in ND. Among them, the rate of increase of MR/MRo in SW was $34.6 \%, 35.5 \%$, and $80.9 \%$ higher than that in NW, SD and ND, respectively.

\section{Discussion}

At present, few studies have examined changes in the photosynthesis of Welsh onions during the summer. In this experiment, to investigate the regulatory mechanisms of onion leaves under high light and drought conditions during summer, we measured the rate of carbon dioxide assimilation using CIRAS-3, PSII energy distribution with Imaging-PAM and the fast fluorescence induction curve and $820 \mathrm{~nm}$ light reflection signal using Handy PEA and M-PEA.

The chlorophyll content is the basis of photoreactions and can be used to measure the light energy absorption and utilization of leaves. Environmental stress leads to a decrease in the chlorophyll content $[3,17,18]$. The leaf pigment content of Welsh onion leaves under high light and drought conditions decreased significantly, and the decreasing trend became more serious with the treatment time. Under the combined high light and drought treatment, a significant drop in $\mathrm{Pn}$ indicated a decrease in photosynthesis in the leaves of Welsh onion. According to the changed direction of $\mathrm{Ci}$, we speculated that the reduction in the Pn of the ND and SD treatments was mainly caused by nonstomatal limiting factors when treated for $20 \mathrm{~d}$, while the Pn of NW decreased because the pores limited photosynthesis. This trend was also found in the daily variation in measurements between treatments. The decrease in $\mathrm{Y}(\mathrm{II})$ under natural light and drought treatment was accompanied by an increase in $\mathrm{Y}(\mathrm{NPQ})$ and a significant increase in $\mathrm{Y}(\mathrm{NO})$ [19]. We hypothesized that the decrease in $\mathrm{Y}(\mathrm{II})$ was mainly due to the decrease in the carbon assimilation ability of the leaves and the excessive accumulation of linear electron transport products, which suppress the linear electron transfer rate[20].

Plants must be able to grow in a changing light environment throughout their life cycle[21]. The intensity of PAR directly affects the photosynthesis of plants, but when the light energy exceeds the need of photosynthesis, a decrease in the efficiency of light energy utilization occurs, causing photoinhibition[22, 23]. Generally, PSII is more sensitive to photoinhibition under conditions of high light and drought compared with PSI[7]. Our results indicated that the fast-induced fluorescence kinetics curve was very sensitive to light intensity and drought stress[9, 24-26]. The entire photosynthetic electron transport chain of Welsh onion leaves was significantly affected under each treatment, but to a slightly different extent. Compared with SW, an increase in $\mathrm{F}_{\mathrm{O}}$ and a decrease in $\mathrm{F}_{\mathrm{m}}$ were observed in ND, SD and NW, indicating a decline in active reaction centers in PSII under drought and high light conditions. Through JIP-test analysis, we obtained the same results, including the increase of $A B S / R C$ and the reduction of $\mathrm{RC} / \mathrm{CS}_{\mathrm{O}}$ and $\mathrm{TR}_{\mathrm{O}} / \mathrm{ABS}$. In addition, some studies have shown that an elevated $\mathrm{F}_{\mathrm{O}}$ caused by drought stress reflects $\mathrm{PSI}$ damage associated with light-harvesting complex II (LHCII) dissociation[27]. Therefore, the dissociation of LHCII may be a cause of the decrease in PSII activity. However, moderate dissociation of LHCII and degradation of the PSII core protein can accelerate the turnover of PSII and stabilize the normal function of PSII[28].

The J-phase appears because $Q_{B}$ cannot accept electrons from $Q_{A}{ }^{-}$in time and thus cannot oxidize $Q_{A}{ }^{-}$, resulting in the accumulation of $Q_{A}{ }^{-}$. $A$ significantly elevated $\mathrm{J}$ phase indicates that electron transport beyond $\mathrm{Q}_{A}{ }^{-}$was limited[29]. We normalized the O-P segment and observed that the ND, SD, and NW treatments showed different degrees of increase in the J-phase compared with SW. $V_{J}$ reflects the closure level of the active reaction center when illuminated for $2 \mathrm{~ms}$, Mo is generally considered to be the rate at which $\mathrm{Q}_{\mathrm{A}}$ is reduced during O-J, and Sm reflects the size of the receptor side PQ pool in the PSII reaction center[25, 26]. $V_{J}$ and Mo increased under natural light, while Sm decreased. These results indicated that the Welsh onion leaves under natural light received too much light energy, which led to the limitation of $Q_{A}{ }^{-}$transport in $P S I I$, and the $P Q$ was reduced by the capacity of the receptor library. The drop in $\mathrm{ET}_{0} / \mathrm{TR}_{0}$ can also verify this result.

The appearance of the K-phase is caused by the inhibition of the water cleavage system and the inhibition of the receptor side portion before $\mathrm{Q}_{\mathrm{A}[30]}$. In this inhibition process, mainly the donor side (OEC) of PSII is damaged, so the increase in K-phase fluorescence is usually used to characterize the damage to the donor side of PSII or OEC[31]. At $20 \mathrm{~d}$, the significant increase in the K-phase of ND indicated that the PSII donor side may be damaged. OEC participates in the photooxidation of water during the photoreaction of photosynthesis[31]. We hypothesize that the water oxidation of Welsh onions under high light and drought treatment was impaired. ND, SD, and NW all had significant K phases compared with that of SW, and $F_{K}, V_{K}$, and $W_{K}$ all increased (Table S2). An increase in $F_{K}$ caused a negative change in the L-band, indicating the detachment of LHCll from the reaction center, which again validates the results of the previous paragraph (the dissociation of LHCII may be a cause of the reduced PSII activity, Fig. S1-B, D). The strong uncoupling of the PSII donor side (OEC) can cause a significant increase in $V_{K}[8,32]$. The increase in $V_{K}$ indicates that the 
manganese clusters of the oxygen-releasing complex may be the cause of the PSIl photoinhibition. $\mathrm{W}_{\mathrm{K}}$ can also be used to reflect the extent of damage to the OEC. According to the calculation formula for $W_{K}$ and previous studies, $W_{K}$ should be used as an indicator to reflect the relative damage of the PSII donor and receptor sides. Binding to the PSII receptor side was also compromised, which may have also caused an increase in $\mathrm{W}_{\mathrm{K}}[33,34]$.

$\mathrm{PI}_{\mathrm{ABS}}$ is a performance index based on absorbed light energy, which can reflect the parameters of plant comprehensive photosynthetic performance and is sensitive to stress, especially drought stress[26]. The $\mathrm{PI}_{A B S}$ was significantly reduced by ND, especially after $20 \mathrm{~d}$ of treatment. $A$ decrease in the $\mathrm{PI}_{\mathrm{ABS}}$ value suggested decreased PSIl activity and ultimately a diminished rate of electron transport through $\mathrm{PQ}$ to $\mathrm{P}_{700}{ }^{+}$.

The $M R / M R_{0}$ is reduced from $M_{0}$ to the minimum level, reflecting the PSI oxidation process, and then increases to the maximum level indicating that the PSI is in the reduction process[12, 26]. After $20 \mathrm{~d}$ of treatment, MR delivery was significantly affected, with the PSI oxidation process shortening and the PSI reduction process was suppressed, as evidenced by the significant decreases in $V_{P S I}$ and $V_{P S I I-P S I}$. However, we need to pay attention to the fact that PSI photoinhibition poses a major threat to the entire photosynthetic mechanism compared to PSII photoinhibition because it is difficult to recover the process and feedback suppression of PSII[21, 35, 36]. The $\varphi R_{0}$ decreased significantly with the ND, SD, and NW treatments (Table S2, reduction efficiency of PSI terminal electron acceptor), indicating that electron transfer between photosystems was suppressed, and the difference between treatments was not significant at $10 \mathrm{~d}$, which may be related to linear electron flow. The effect was not significant in the early treatment stage but was strongly suppressed in the later stages of treatment. Surprisingly, the SW treatment significantly reduced the PSI terminal electron acceptor-reduced electron flow $\mathrm{RE}_{0} / \mathrm{RC}$ (Table S2) at $10 \mathrm{~d}$, while the difference between the treatments was eliminated at $20 \mathrm{~d}$. We hypothesize that under the conditions of donor side restriction, the stability of PSI terminal electron acceptor reduction is likely to be due to the presence of circular electron transport around PSI[12].

\section{Conclusions}

High light and drought treatment can lead to a decrease in the leaf pigment content and net photosynthetic rate during summer. By measuring the OJIP and MR curves, we observed a large amount of environmental stress-induced changes in the photosynthetic electron transport chain. High light and drought stress damaged multiple sites in the electron transport chain. The dual stresses deactivated the PSII reaction center, hindered electron transfer between $\mathrm{Q}_{\mathrm{A}}$ and $\mathrm{Q}_{\mathrm{B}}$, caused OEC damage, reduced connectivity between independent PSII units, and inhibited electron transfer between optical systems, ultimately leading to the imbalance between PSII and PSI.

\section{Abbreviations}

$\mathrm{Ci}$, substomatal $\mathrm{CO}_{2}$ concentrations; $C y t b_{6} f$, the cytochrome $b_{6} f$ complex; Fd, ferredoxin; $F_{m}$, the maximum PF intensity; Fo, the minimum PF intensity; Gs, stomatal conductance; LHCIl, the light-harvesting complex II, MR, modulated $820 \mathrm{~nm}$ reflection; OEC complex, oxygen-releasing complex; PAR, photosynthetically active radiation; PC, plastocyanin; PF, prompt chlorophyll a fluorescence; PFD, photon flux density; Pn, net photosynthetic rate; $\mathrm{PQ}$, plastoquinone; $\mathrm{PSI}$, photosystem I; PSII, photosystem II; P680, PSII reaction center; P700, PSI reaction center; Y(NPQ), the quantum yield of regulated energy dissipation; $\mathrm{Y}(\mathrm{NO})$, the quantum yield of nonregulated energy dissipation; $\mathrm{Y}(\mathrm{II})$, the effective PSII quantum yield; $\mathrm{V}_{\mathrm{PS}}$, maximum slope decrease of $\mathrm{MR} / \mathrm{MR}_{0} ; \mathrm{V}_{\mathrm{PSII}-\mathrm{PS} \text {, }}$ maximum slope increase of $M R / \mathrm{MR}_{\mathrm{O}}$.

\section{Declarations}

\section{Availability of data and material}

The datasets used and/or analyzed during the current study are available from the corresponding author on reasonable request.

\section{Acknowledgements}

Not applicable.

\section{Funding}

This study was supported by the National Characteristic Vegetable Industry Technology System Project (Grant No. CARS-24-A-09), the Double FirstClass Discipline Construction Project of Shandong Province (No. SYL2017YSTD06) and the Agricultural Variety Project of Science and Technology Department of Shandong Province (No. 2016LZGC015). 
Authors' contributions

KX and XNL designed the research. XNL and SG performed the experiments. XNL and YL analyzed the data. XNL wrote the manuscript, and KX revised the intellectual content of this manuscript. All authors read and approved the final manuscript.

\section{Author details}

a College of Horticulture Science and Engineering, Shandong Agricultural University, Tai'an, 271018, P.R. China, b Collaborative Innovation Center of Fruit \& Vegetable Quality and Efficient Production in Shandong, P.R. China, ${ }^{c}$ Key Laboratory of Biology and Genetic Improvement of Horticultural Crops in Huanghuai Region, Ministry of Agriculture and Rural Affairs, P.R. China, ${ }^{d}$ State Key Laboratory of Crop Biology, Ministry of Agriculture, P.R. China, ${ }^{*}$ Corresponding author.

Ethics approval and consent to participate

Not applicable.

\section{Consent for publication}

Not applicable.

\section{Competing interests}

The authors declare that they have no competing interests.

\section{References}

1. Zi-ying H, Jun-ju Z, LI-LI Z, Wei W, Jian-jun C: Climate dry-wet and drought evolution characteristics of different dry-wet areas in northern China. Acta Ecologica Sinica 2018, 38(06):1908-1919.

2. Gilbert ME, Zwieniecki MA, Holbrook NM: Independent variation in photosynthetic capacity and stomatal conductance leads to differences in intrinsic water use efficiency in 11 soybean genotypes before and during mild drought. Journal of Experimental Botany 2011, 62(8):2875-2887.

3. Gilbert ME, Medina V: Drought Adaptation Mechanisms Should Guide Experimental Design. Trends in Plant Science 2016, 21(8):639-647.

4. Niyogi KK: Photoprotection revisited: genetic and molecular approaches. Annual Review of Plant Physiology and Plant Molecular Biology 1999, 50(1):333-359.

5. S P Long, S Humphries a, Falkowski PG: Photoinhibition of Photosynthesis in Nature. Annual Review of Plant Physiology and Plant Molecular Biology 1994, 45(1):633-662.

6. Lawlor DW, Cornic G: Photosynthetic carbon assimilation and associated metabolism in relation to water deficits in higher plants. Plant, Cell \& Environment 2002, 25(2):275-294.

7. Yang XQ, Zhang QS, Zhang D, Sheng ZT: Light intensity dependent photosynthetic electron transport in eelgrass (Zostera marina L.). Plant Physiology and Biochemistry 2017, 113:168-176.

8. Shen J-R, Terashima I, Katoh S: Cause for Dark, Chilling-Induced Inactivation of Photosynthetic Oxygen-Evolving System in Cucumber Leaves. Plant Physiology 1990, 93(4):1354-1357.

9. Strasser R, Srivastava A, Tsimilli-Michael M: The fluorescence transient as a tool to characterize and screen photosynthetic samples; 2000.

10. Gollan Peter J, Lima-Melo Y, Tiwari A, Tikkanen M, Aro E-M: Interaction between photosynthetic electron transport and chloroplast sinks triggers protection and signalling important for plant productivity. Philosophical Transactions of the Royal Society B: Biological Sciences 2017, 372(1730):20160390.

11. Walker BJ, Busch FA, Driever SM, Kromdijk J, Lawson T: Survey of Tools for Measuring In Vivo Photosynthesis. In: Photosynthesis: Methods and Protocols. Edited by Covshoff S. New York, NY: Springer New York; 2018: 3-24. 
12. Strasser RJ, Tsimilli-Michael M, Qiang S, Goltsev V: Simultaneous in vivo recording of prompt and delayed fluorescence and 820-nm reflection changes during drying and after rehydration of the resurrection plant Haberlea rhodopensis. Biochimica et Biophysica Acta (BBA) Bioenergetics 2010, 1797(6):1313-1326.

13. Schansker G, Srivastava A, Govindjee, Strasser RJ: Characterization of the 820-nm transmission signal paralleling the chlorophyll a fluorescence rise (OJIP) in pea leaves. Functional Plant Biology 2003, 30(7):785-796.

14. Zhao S, Shi GA, Dong XC: Plant Physiology Experiment Report. Beijing: Chinese Agriculture Science \& Technology Press; 2002.

15. Hendrickson L, Förster B, Furbank RT, Chow WS: Processes contributing to photoprotection of grapevine leaves illuminated at low temperature. Physiologia Plantarum 2004, 121(2):272-281.

16. Straaer BJ: Measuring fast fluorescence transients to address environmental questionsL,the JIP-test. Photosynthesis:from Light to Biosphere 1995:977-980.

17. Larkunthod P, Nounjan N, Siangliw JL, Toojinda T, Sanitchon J, Jongdee B, Theerakulpisut P: Physiological responses under drought stress of improved drought-tolerant rice lines and their parents. Notulae Botanicae Horti Agrobotanici Cluj-Napoca 2018, 46(2):679-687.

18. Rapacz M, Wójcik-Jagła M, Fiust A, Kalaji HM, Kościelniak J: Genome-Wide Associations of Chlorophyll Fluorescence OJIP Transient Parameters Connected With Soil Drought Response in Barley. Frontiers in plant science 2019, 10:78-78.

19. G H Krause, Weis E: Chlorophyll Fluorescence and Photosynthesis: The Basics. Annual Review of Plant Physiology and Plant Molecular Biology 1991, 42(1):313-349.

20. Durand M, Brendel O, Buré C, Le Thiec D: Altered stomatal dynamics induced by changes in irradiance and vapour-pressure deficit under drought: impacts on the whole-plant transpiration efficiency of poplar genotypes. New Phytologist 2019, 222(4):1789-1802.

21. Li P, Ma F: Different effects of light irradiation on the photosynthetic electron transport chain during apple tree leaf dehydration. Plant Physiology and Biochemistry 2012, 55:16-22.

22. Yong-zheng Z, Hai-dong L, Xiu L, Jing X, Kun X: Effects of Light Intensity and Water Stress on Leaf Photoysnthetic Chatacteristics of Ginger. Acta Horticulturae Sinica 2013, 40(11):2255-2262.

23. Mathur S, Jajoo A: Alterations in photochemical efficiency of photosystem II in wheat plant on hot summer day. Physiology and Molecular Biology of Plants 2014, 20(4):527-531.

24. Stirbet A, Govindjee: On the relation between the Kautsky effect (chlorophyll a fluorescence induction) and Photosystem II: Basics and applications of the OJIP fluorescence transient. Journal of Photochemistry and Photobiology B: Biology 2011, 104(1):236-257.

25. Kalaji HM, Račková L, Paganová V, Swoczyna T, Rusinowski S, Sitko K: Can chlorophyll-a fluorescence parameters be used as bio-indicators to distinguish between drought and salinity stress in Tilia cordata Mill? Environmental and Experimental Botany 2018, 152:149-157.

26. Liu J, Guo YY, Bai YW, Camberato JJ, Xue JQ, Zhang RH: Effects of drought stress on the photosynthesis in Maize. Russian Journal of Plant Physiology 2018, 65(6):849-856.

27. Briantais J-M, Dacosta J, Goulas Y, Ducruet J-M, Moya I: Heat stress induces in leaves an increase of the minimum level of chlorophyll fluorescence, Fo: A time-resolved analysis. Photosynthesis Research 1996, 48(1):189-196.

28. Oukarroum A, Madidi SE, Schansker G, Strasser RJ: Probing the responses of barley cultivars (Hordeum vulgare L.) by chlorophyll a fluorescence OLKJIP under drought stress and re-watering. Environmental and Experimental Botany 2007, 60(3):438-446.

29. Li P, Cheng L, Gao H, Jiang C, Peng T: Heterogeneous behavior of PSIl in soybean (Glycine max) leaves with identical PSIl photochemistry efficiency under different high temperature treatments. Journal of Plant Physiology 2009, 166(15):1607-1615.

30. Wang Y, Zhang B, Jiang D, Chen G: Silicon improves photosynthetic performance by optimizing thylakoid membrane protein components in rice under drought stress. Environmental and Experimental Botany 2019, 158:117-124.

31. Yan K, Chen P, Shao H, Shao C, Zhao S, Brestic M: Dissection of Photosynthetic Electron Transport Process in Sweet Sorghum under Heat Stress. PLOS ONE 2013, 8(5):e62100.

32. Kaniuga Z, Ząbek J, Sochanowicz B: Photosynthetic apparatus in chilling-sensitive plants : III. Contribution of loosely bound manganese to the mechanism of reversible inactivation of hill reaction activity following cold and dark storage and illumination of Leaves. Planta 1978 , 144(1):49-56.

33. Strasser BJ: Donor side capacity of Photosystem II probed by chlorophyll a fluorescence transients. Photosynthesis Research 1997, 52(2):147155.

34. Jin L-Q, Che X-K, Zhang Z-S, Gao H-Y: The relationship between the changes in Wk and different damage degree of PSII donor side and acceptor side under high temperature with high light in Cucumber. Plant Physiology Journal 2015, 51(6):969-976.

35. Sonoike K: Photoinhibition of photosystem I. Physiologia Plantarum 2011, 142(1):56-64.

36. Salvatori E, Fusaro L, Strasser RJ, Bussotti F, Manes F: Effects of acute 03 stress on PSII and PSI photochemistry of sensitive and resistant snap bean genotypes (Phaseolus vulgaris L.), probed by prompt chlorophyll "a" fluorescence and 820 nm modulated reflectance. Plant Physiology and Biochemistry 2015, 97:368-377. 


\section{Tables}

Table 1 Effects of different light intensity and drought treatments on leaf pigment and gas exchange parameters, including the net photosynthetic rate (Pn), intercellular $\mathrm{CO}_{2}$ concentration (Ci) and stomatal conductance (Gs). The data are from three replicated experiments $(\mathrm{n}=3)$ and represent means $\pm \mathrm{SD}$. Different letters indicate significant differences between different treatments.

\begin{tabular}{ccccccc}
\hline Days after treatment & Treatment & Chlorophylls $\left(\mu \mathrm{g} / \mathrm{cm}^{2}\right)$ & Carotenoids & Pn $\left(\mu \mathrm{mol} / \mathrm{m}^{2} / \mathrm{s}\right)$ & $\mathrm{Ci}(\mu \mathrm{mol} / \mathrm{mol})$ & $\mathrm{Gs}(\mathrm{mmol} / \mathrm{mol})$ \\
& \multicolumn{5}{c}{$\left(\mu \mathrm{g} / \mathrm{cm}^{2}\right)$} \\
\hline \multirow{2}{*}{$10 \mathrm{~d}$} & ND & $31.94 \pm 0.51 \mathrm{~d}$ & $4.45 \pm 0.13 \mathrm{~b}$ & $3.63 \pm 0.06 \mathrm{~d}$ & $280.33 \pm 2.31 \mathrm{~b}$ & $64.00 \pm 5.29 \mathrm{~d}$ \\
& NW & $39.49 \pm 0.76 \mathrm{~b}$ & $5.64 \pm 0.18 \mathrm{a}$ & $10.23 \pm 0.12 \mathrm{~b}$ & $289.00 \pm 7.81 \mathrm{ab}$ & $198.33 \pm 8.62 \mathrm{~b}$ \\
& SD & $33.52 \pm 0.67 \mathrm{c}$ & $4.87 \pm 0.23 \mathrm{~b}$ & $6.47 \pm 0.12 \mathrm{c}$ & $328.67 \pm 40.25 \mathrm{a}$ & $135.67 \pm 11.59 \mathrm{c}$ \\
& SW & $42.25 \pm 0.27 \mathrm{a}$ & $5.99 \pm 0.04 \mathrm{a}$ & $14.40 \pm 0.01 \mathrm{a}$ & $266.67 \pm 3.51 \mathrm{~b}$ & $217.33 \pm 15.04 \mathrm{a}$ \\
\hline & ND & $28.31 \pm 0.09 \mathrm{~d}$ & $4.17 \pm 0.12 \mathrm{c}$ & $1.87 \pm 0.38 \mathrm{~d}$ & $304.67 \pm 9.87 \mathrm{ab}$ & $49.67 \pm 11.93 \mathrm{c}$ \\
& NW & $31.45 \pm 0.43 \mathrm{~b}$ & $4.32 \pm 0.12 \mathrm{bc}$ & $8.13 \pm 0.21 \mathrm{~b}$ & $248.67 \pm 4.93 \mathrm{c}$ & $115.67 \pm 2.52 \mathrm{~b}$ \\
& SD & $29.13 \pm 0.16 \mathrm{c}$ & $4.51 \pm 0.12 \mathrm{~b}$ & $4.13 \pm 0.12 \mathrm{c}$ & $321.33 \pm 12.06 \mathrm{a}$ & $124.67 \pm 2.52 \mathrm{~b}$ \\
& SW & $42.23 \pm 0.59 \mathrm{a}$ & $5.74 \pm 0.04 \mathrm{a}$ & $13.6 \pm 0.17 \mathrm{a}$ & $300.67 \pm 2.08 \mathrm{~b}$ & $413.67 \pm 14.47 \mathrm{a}$ \\
\hline
\end{tabular}

Table 2 Effects of different light intensity and drought treatments on the JIP-test parameters. The data are from three replicated experiments ( $\mathrm{n}=3$ ) and represent means \pm SD. Different letters indicate significant differences between different treatments.

\begin{tabular}{|c|c|c|c|c|c|c|c|c|c|c|c|c|}
\hline $\begin{array}{c}\text { Days } \\
\text { after } \\
\text { treatment }\end{array}$ & Treatment & $\mathrm{F}_{\mathrm{O}}$ & $\mathrm{F}_{\mathrm{m}}$ & $\overline{V_{J}}$ & $\mathrm{~W}_{\mathrm{K}}$ & $\mathrm{S}_{\mathrm{m}}$ & $\mathrm{M}_{\mathrm{O}}$ & $\mathrm{ABS} / \mathrm{RC}$ & $\mathrm{RC} / \mathrm{CS}$ & $\mathrm{TR}_{\mathrm{O}} / \mathrm{ABS}$ & $\mathrm{ET}_{\mathrm{O}} / \mathrm{TR}_{\mathrm{O}}$ & $\mathrm{PI}_{\mathrm{ABS}}$ \\
\hline \multirow[t]{8}{*}{$10 \mathrm{~d}$} & ND & $541 \pm 36$ & $2240 \pm 241$ & $0.41 \pm 0.02$ & $0.32 \pm 0.06$ & $33.52 \pm 0.99$ & $0.96 \pm 0.45$ & $2.49 \pm 0.15$ & $206 \pm 106$ & $0.76 \pm 0.01$ & $0.59 \pm 0.02$ & $1.83 \pm 0.13$ \\
\hline & & aA & cB & $\mathrm{aA}$ & $\mathrm{aA}$ & $\mathrm{aA}$ & $\mathrm{aA}$ & $\mathrm{aA}$ & $\mathrm{aA}$ & $\mathrm{dD}$ & bA & cC \\
\hline & NW & $515 \pm 8$ & $2639 \pm 50$ & $0.39 \pm 0.01$ & $0.31 \pm 0.01$ & $27.68 \pm 1.28$ & $0.89 \pm 0.05$ & $2.37 \pm 0.08$ & $182 \pm 15$ & $0.8 \pm 0.01$ & $0.61 \pm 0.01$ & $2.77 \pm 0.09$ \\
\hline & & $\mathrm{aA}$ & abA & abA & aA & bAB & $\mathrm{aA}$ & $\mathrm{aAB}$ & aA & bB & abA & bB \\
\hline & SD & $543 \pm 7$ & $2533 \pm 59$ & $0.4 \pm 0.01$ & $0.33 \pm 0.04$ & $25.58 \pm 2.37$ & $0.95 \pm 0.14$ & $2.52 \pm 0.22$ & $181 \pm 30$ & $0.79 \pm 0.01$ & $0.6 \pm 0.01$ & $2.21 \pm 0.16$ \\
\hline & & aA & bAB & aA & aA & bB & aA & aA & aA & cC & bA & $\mathrm{cC}$ \\
\hline & SW & $456 \pm 5$ & $2841 \pm 43$ & $0.37 \pm 0.01$ & $0.25 \pm 0.01$ & $27.17 \pm 0.68$ & $0.71 \pm 0.04$ & $1.91 \pm 0.04$ & $200 \pm 14$ & $0.84 \pm 0.01$ & $0.63 \pm 0.01$ & $4.65 \pm 0.21$ \\
\hline & & $\mathrm{bB}$ & $\mathrm{aA}$ & bA & $\mathrm{aA}$ & $\mathrm{bAB}$ & $\mathrm{aA}$ & $\mathrm{bB}$ & $\mathrm{aA}$ & $\mathrm{aA}$ & $\mathrm{aA}$ & aA \\
\hline \multirow[t]{8}{*}{$20 \mathrm{~d}$} & ND & $586 \pm 12$ & $2106 \pm 103$ & $0.46 \pm 0.01$ & $0.4 \pm 0.02$ & $24.27 \pm 0.68$ & $1.17 \pm 0.17$ & $2.49 \pm 0.15$ & $168 \pm 31$ & $0.72 \pm 0.01$ & $0.53 \pm 0.01$ & $1.04 \pm 0.05$ \\
\hline & & aA & cB & aA & aA & bB & aA & aA & aA & $\mathrm{dD}$ & bB & $\mathrm{cC}$ \\
\hline & NW & $525 \pm 14$ & $2342 \pm 83$ & $0.38 \pm 0.01$ & $0.31 \pm 0.01$ & $25.86 \pm 1.41$ & $0.88 \pm 0.11$ & $2.37 \pm 0.08$ & $178 \pm 27$ & $0.78 \pm 0.01$ & $0.62 \pm 0.01$ & $2.28 \pm 0.04$ \\
\hline & & bB & bB & bB & bcAB & bAB & bcAB & $\mathrm{aAB}$ & aA & bB & aA & bB \\
\hline & SD & $569 \pm 7$ & $2332 \pm 52$ & $0.45 \pm 0.04$ & $0.35 \pm 0.01$ & $24.47 \pm 0.86$ & $1.06 \pm 0.05$ & $2.52 \pm 0.22$ & $186 \pm 11$ & $0.76 \pm 0.01$ & $0.54 \pm 0.04$ & $1.45 \pm 0.16$ \\
\hline & & aA & bB & aA & abAB & bB & abAB & aA & aA & cC & bB & cBC \\
\hline & SW & $452 \pm 20$ & $2729 \pm 127$ & $0.35 \pm 0.01$ & $0.26 \pm 0.05$ & $30.98 \pm 3.48$ & $0.7 \pm 0.13$ & $1.91 \pm 0.04$ & $197 \pm 50$ & $0.83 \pm 0.01$ & $0.65 \pm 0.01$ & $4.69 \pm 0.56$ \\
\hline & & $\mathrm{cC}$ & $\mathrm{aA}$ & $\mathrm{bB}$ & cB & $\mathrm{aA}$ & $\mathrm{cB}$ & $\mathrm{bB}$ & aA & $\mathrm{aA}$ & $\mathrm{aA}$ & $\mathrm{aA}$ \\
\hline
\end{tabular}

Table 3 Parameters derived from the modulated $820 \mathrm{~nm}$ reflection $\left(\mathrm{MR} / \mathrm{MR}_{\mathrm{O}}\right)$ curve of the different treatments on the $10^{\text {th }}$ and $20^{\text {th }} \mathrm{d}$ of treatment. $\mathrm{V}_{\mathrm{PSI}}$ was the maximum decrease in the slope of MR/MR , and $\mathrm{V}_{\mathrm{PSII}-\mathrm{PSI}}$ was the maximum increase in the slope of $\mathrm{MR} / \mathrm{MR}_{\mathrm{O}}$. The data are from three replicated experiments $(n=3)$ and represent means \pm SD. Different letters indicate significant differences between different treatments.

\begin{tabular}{cccc}
\hline Days after treatment & Treatment & $\mathrm{V}_{\mathrm{PSI}} \times 10^{3}$ & $\mathrm{~V}_{\mathrm{PSII}-\mathrm{PSI}} \times 10^{3}$ \\
\hline \multirow{2}{*}{$10 \mathrm{~d}$} & $\mathrm{ND}$ & $3.47 \pm 0.22 \mathrm{cC}$ & $5.16 \pm 0.38 \mathrm{bB}$ \\
\cline { 2 - 4 } & $\mathrm{NW}$ & $4.61 \pm 0.09 \mathrm{bB}$ & $7.80 \pm 0.49 \mathrm{aA}$ \\
\cline { 2 - 3 } $20 \mathrm{~d}$ & $\mathrm{SD}$ & $4.34 \pm 0.06 \mathrm{bB}$ & $6.90 \pm 0.66 \mathrm{aA}$ \\
\hline & $\mathrm{SW}$ & $5.10 \pm 0.26 \mathrm{aA}$ & $7.86 \pm 0.57 \mathrm{aA}$ \\
\hline $\mathrm{ND}$ & $2.70 \pm 0.03 \mathrm{cB}$ & $4.59 \pm 0.40 \mathrm{cC}$ \\
& $\mathrm{NW}$ & $3.72 \pm 0.02 \mathrm{bB}$ & $6.16 \pm 0.33 \mathrm{bB}$ \\
\hline $\mathrm{SD}$ & $3.39 \pm 0.12 \mathrm{bB}$ & $6.12 \pm 0.08 \mathrm{bB}$ \\
\hline & $\mathrm{SW}$ & $5.27 \pm 0.57 \mathrm{aA}$ & $8.30 \pm 0.08 \mathrm{aA}$ \\
\hline
\end{tabular}

\section{Figures}




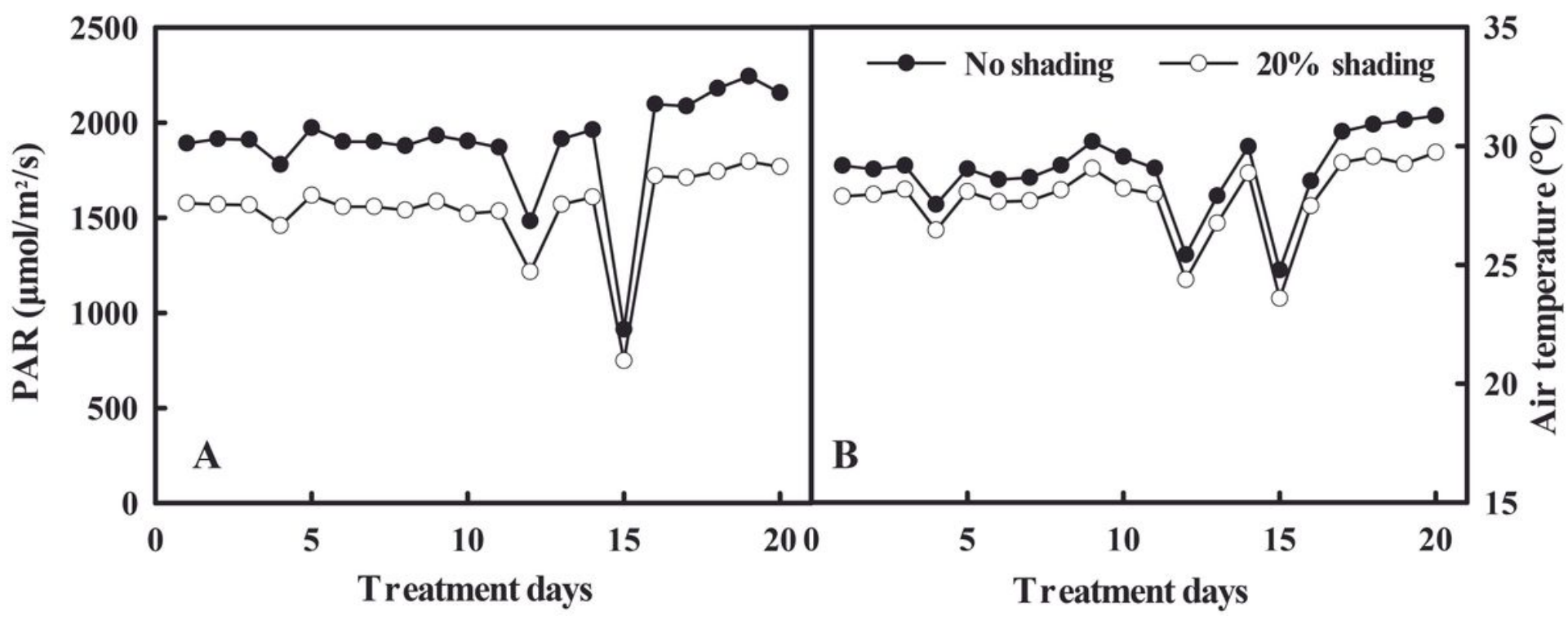

Figure 1

Photosynthetically active radiation (PAR) and air temperature during the experimental period. PAR (A) and air temperature (B) in the no shading (closed circles) and 20\% shading (open circles) treatments. Each point represents the highest PAR or average air temperature of each day.

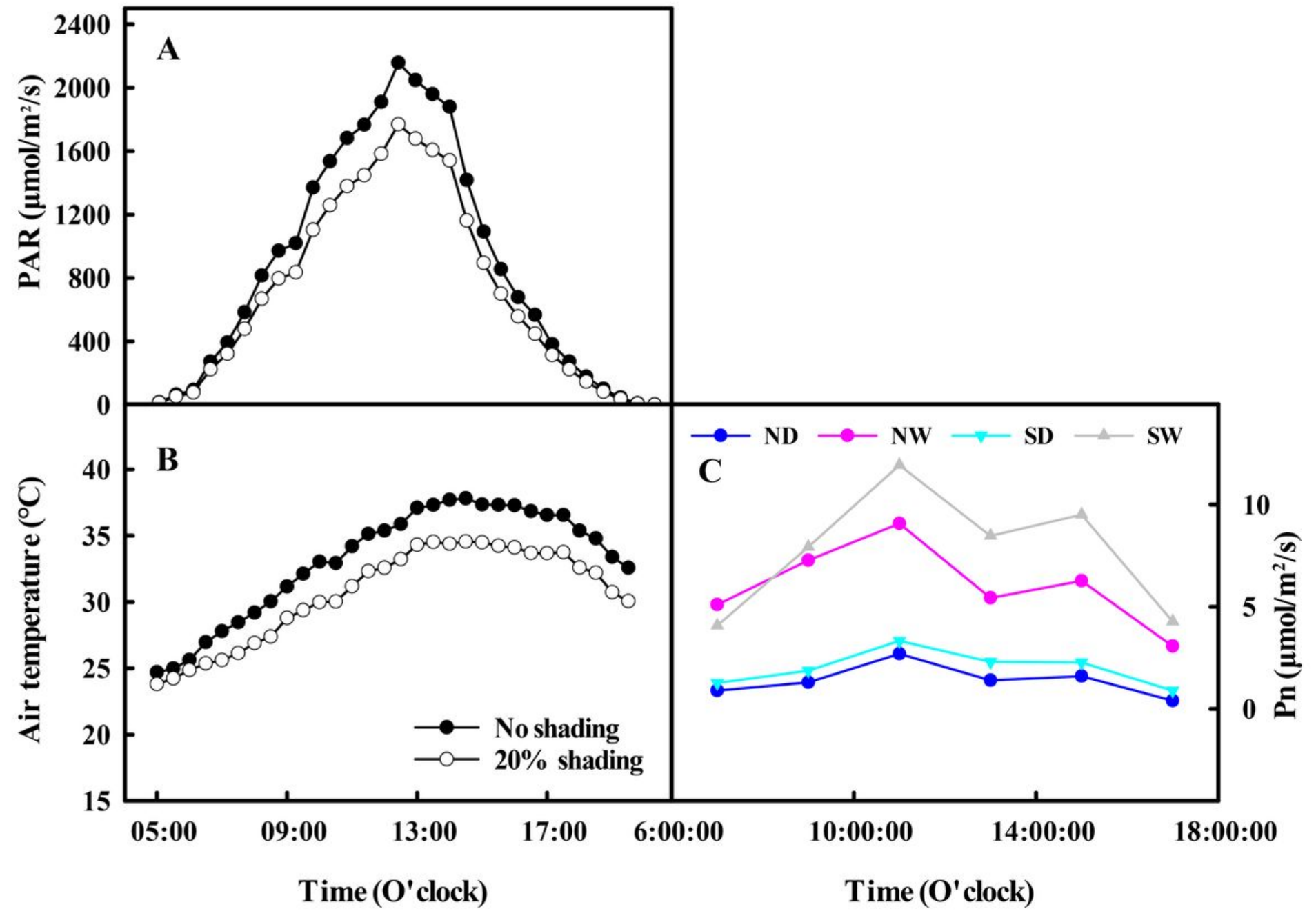

Figure 2 
The diurnal variation in the net photosynthetic rate, PAR and air temperature on the 20th d. Average half-hourly PAR (A) and air temperature (B) within the 20th day in the no shading (closed circles) and $20 \%$ shading (open circles) treatments. (C) The diurnal variation in the net photosynthetic rate $(\mathrm{Pn})$ on the 20th day.

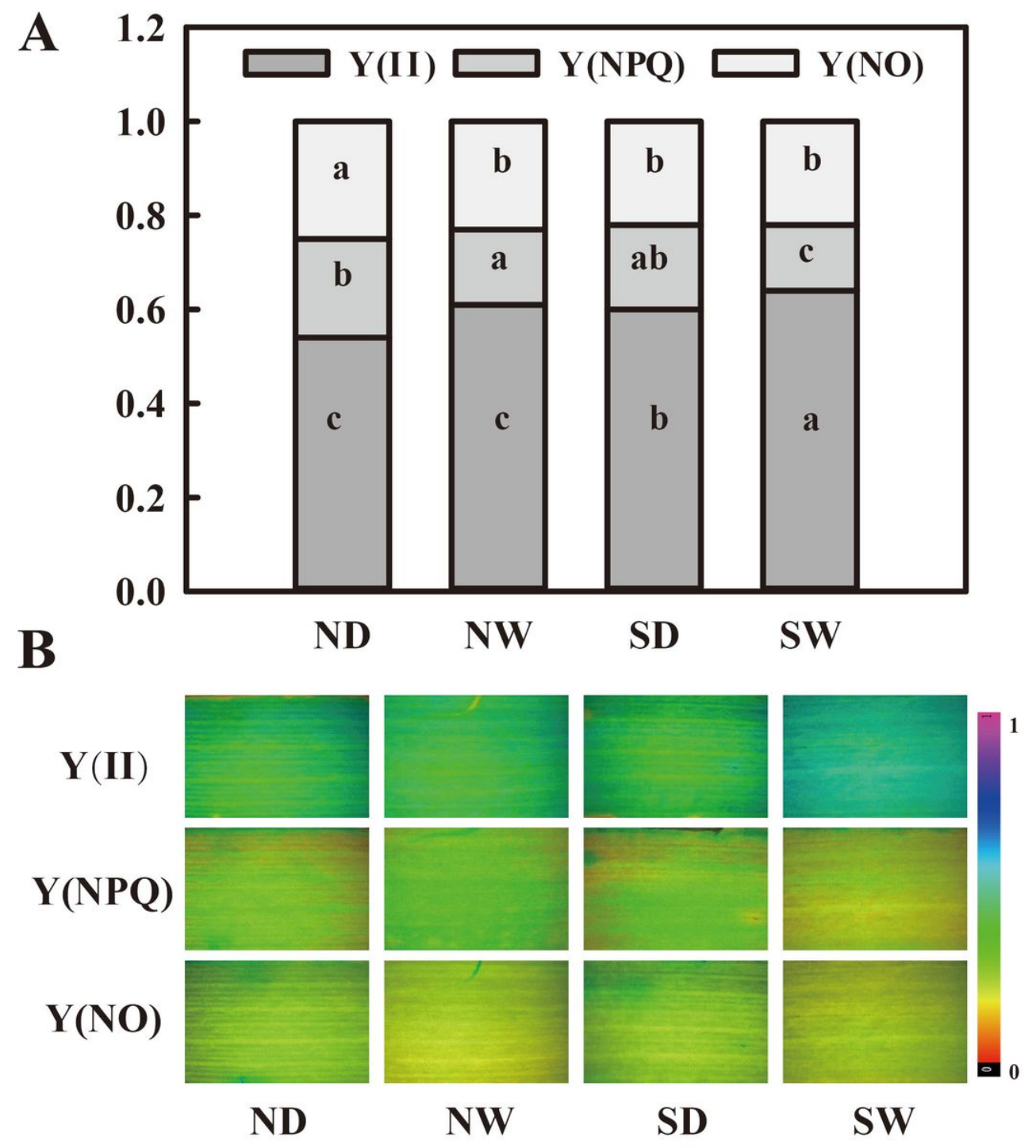

Figure 3

Effects of different light intensity and drought treatments on the quantum efficiencies of PSII. The quantum efficiencies of PSII (A) and associated images $(B)$ on the 20th d of treatment. The data are from three replicated experiments $(n=3)$. Different letters indicate significant differences between different treatments. 

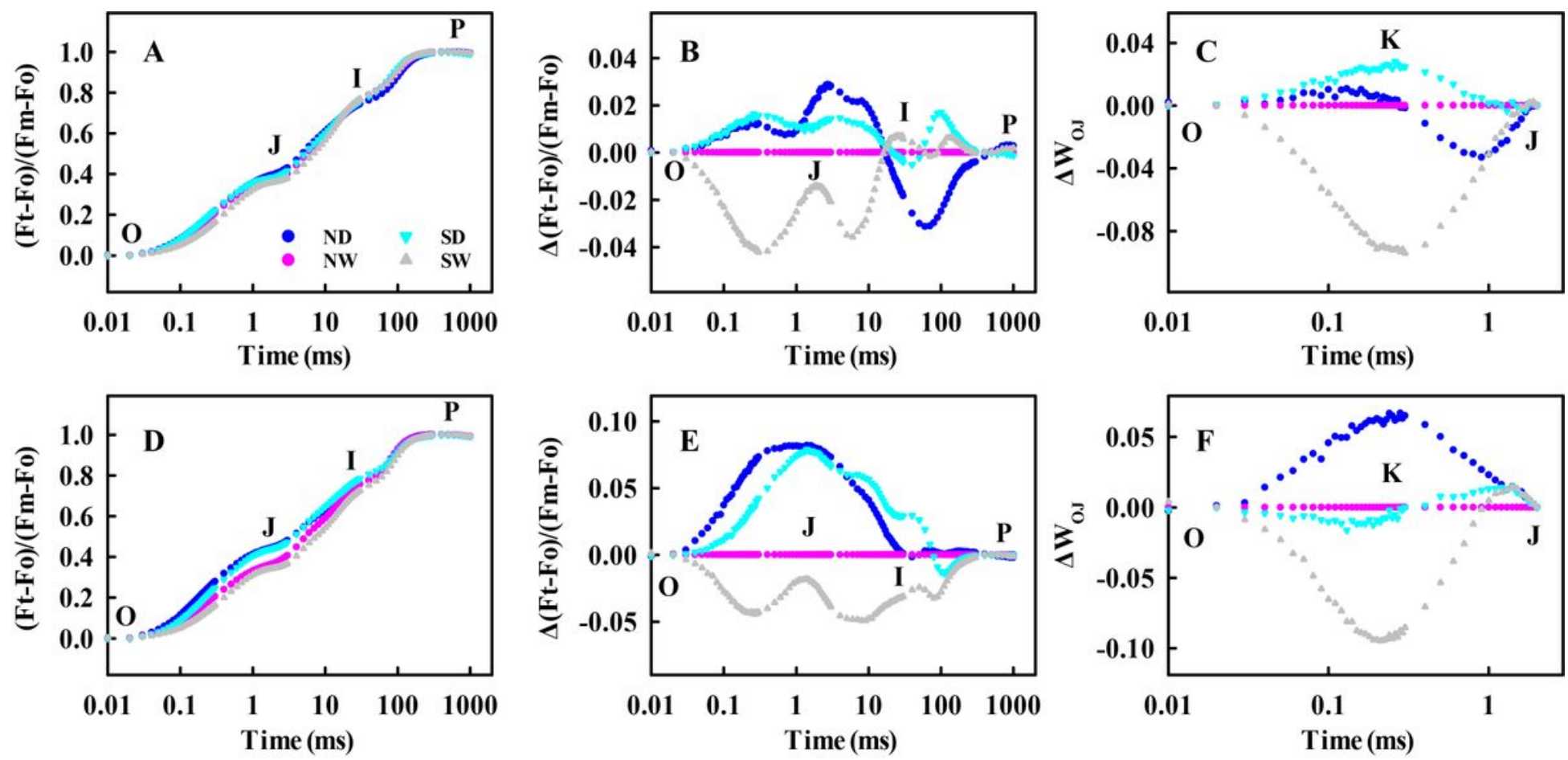

Figure 4

Effects of different light intensity and drought treatments on the OJIP transients. Normalized transients at the 10th (A) and 20th d (D), expressed as $\mathrm{Vt}=[(\mathrm{Ft}-\mathrm{FO}) /(\mathrm{Fm}-\mathrm{FO})]$. The $\Delta \mathrm{Vt}$ curves at the 10th (B) and 20th d (E) expressed as $\Delta \mathrm{Vt}=[(\mathrm{Ft}-\mathrm{FO}) /(\mathrm{Fm}-\mathrm{FO})] \mathrm{T}-[(\mathrm{Ft}-\mathrm{FO}) /(\mathrm{Fm}-\mathrm{FO})] \mathrm{NW}$. (C) Normalized curves between FO and FJ, and their difference in kinetics (K-band) at the 10th (C) and 20th d (F) expressed as $\Delta$ WOJ=[(Ft-FO)/(FJ-FO)]T-[(FtFO)/(FJ-FO)]NW. The data are from three replicated experiments $(n=3)$.
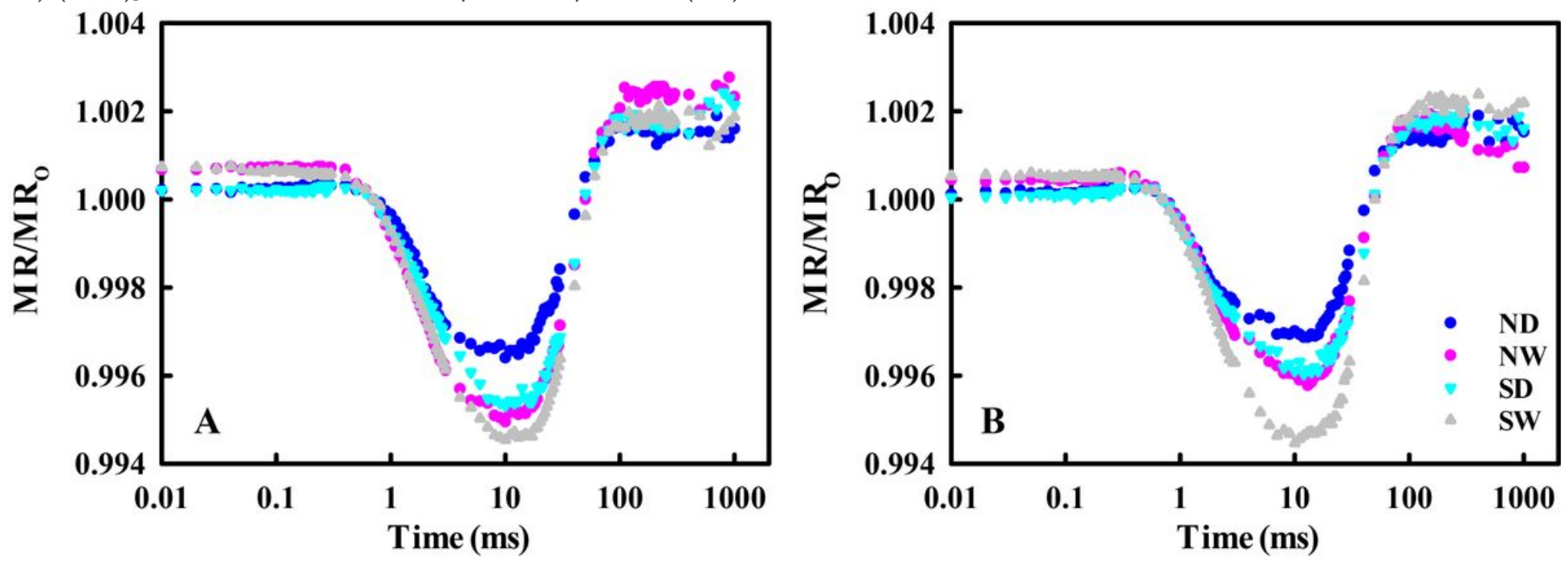

Figure 5

Effects of different light intensity and drought treatments on the MR curves. Kinetics of modulated light reflection at $820 \mathrm{~nm}$ (MR/MRO) in darkadapted leaves based on different treatments at the 10th $(A)$ and 20th $d(B)$ of treatment. All data are normalized to the initial measured value of the signal. The data are presented in relative units. The data are from three replicated experiments $(n=3)$.

\section{Supplementary Files}

This is a list of supplementary files associated with this preprint. Click to download.

- supplement1.docx 